\title{
Microcrystalline cellulose as filler in polycaprolactone matrices
}

\author{
M.E.Alemán-Domínguez, Z. Ortega, A.N.Benítez \& M. Monzón \\ University of Las Palmas de Gran Canaria, Las Palmas de Gran Canaria, Spain
}

L. Wang
University Xi'an Jiaotong, Xi'an, China

M. Tamaddon \&C. Liu

University College London, London, United Kingdom

ABSTRACT: Polycaprolactone is a biomaterial widely used for tissue engineering applications. However, its hydrophobicity hinders cell attachment and proliferation on its surface. In this study microcrystalline cellulose has been proposed as a functional filler for polycaprolactone matrices expected to improve these properties. Composite material samples containing 0, 2, 5, 10 and $20 \%$ $\mathrm{w} / \mathrm{w}$ of microcrystalline cellulose have been manufactured by compression molding and evaluated in terms of their mechanical properties, swelling behavior, water contact angle values and sheep mesenchymal cells viability. The results confirm that the presence of the additive is able to increase the swelling ability of the material (the samples containing $20 \% \mathrm{w} / \mathrm{w}$ of additive are able to absorb an amount of water 6 times higher than the value for polycaprolactone ones), the Young's modulus (from $224 \pm 14 \mathrm{MPa}$ for polycaprolactone to $388 \pm 30 \mathrm{MPa}$ for the composites containing $20 \%$ of microcrystalline cellulose) and the bioaffinity of polycaprolactone based composite materials.

\section{INTRODUCTION}

Polycaprolactone has been one of the most explored materials to be used as scaffolding in bone regeneration. However, its lack of hydrophilicity hinders the cell attachment and proliferation (Mondal et al. 2016, Mirhosseini et al. 2016, Mehr et al. 2015). Different alternatives have been explored in order to improve the hydrophilicity of this material. Filling the polycaprolactone matrix with additives has been one of them. Ceramic fillers have been the most explored options, especially bioactive ceramics (Park 2011, Domingos et al. 2017, Nyberg 2017,Lin et al. 2018, Tsai et al. 2017). However, less attention has been paid to organic additives, although some of them could be interesting options in order to improve simultaneously the mechanical properties of the matrix and its water affinity. The authors of this paper have previously proposed the introduction of carboxymethylcellulose (CMC) (Alemán-Domínguez et al. 2018a). CMC was confirmed as a suitable additive in order to modify the hydrophilicity of the polycaprolactone matrix. However, the cell affinity did not show a similar trend, as no significant modification was observed for the composite materials compared to pure polycaprolactone. In this study, another organic additive has been proposed as a functional filler of polycaprolactone matrices: microcrystalline cellulose (MCC).

Microcrystalline cellulose has been used as a reinforcement additive in thermoplastic matrices for industrial applications (Izzati et al. 2015, Haafiz et al. 2013). However, the suitability of this additive for biomaterials aimed to be used in Tissue Engineering has been barely explored. The authors of this paper (Alemán-Domínguez et al. 2018b) have already shown the potential of the composites based on polycaprolactone:microcrystalline cellulose blends to obtain 3D printed scaffolds. However, the behavior of those 3D printed scaffolds can be affected not only by the material properties, but 
also by the quality of the 3D printing process. The influence of the 3D printing parameters on the characteristics of the structures was demonstrated by Drummer et al. (Drummer et al. 2012), who concluded that the processing temperature can change the crystallinity of polylactid acid 3D printed structures and, as a consequence, their mechanical properties.

Therefore, the evaluation of the bulk properties of the composites obtained by filling this additive in polycaprolactone matrices is highly relevant in order to understand the relevance of the materials properties on the improvement of the matrix to be used as a support biomaterial in Tissue Engineering applications. Herein, we present such an evaluation with bulk samples of polycaprolactone:microcrystalline cellulose composite materials, so the results of this study are complementary to the previous work and, moreover, they could be used as essential information to extrapolate the data for exploring other manufacturing techniques.

\section{MATERIALS AND METHODS}

\subsection{Materials}

Polycaprolactone (PCL) Capa ${ }^{\circledR} 6800$ with mean molecular weight 80000 Da was kindly supplied by Perstorp, UK. Microcrystalline cellulose (MCC) was purchased from Sigma Aldrich. The following reagents were used for cell culture: DMEM low glucose (Sigma-Aldrich, UK), $100 \mathrm{units} / \mathrm{ml}$ penicillinstreptomycin (P/S Gibco, UK), PBS, phosphate buffered saline (Life Technologies), fetal calf serumcolumbia (First Direct, First Link, UK), trypsin-EDTA (0.5\%) (Thermo Fisher Scientific).

\subsection{Preparation of composite materials}

The polycaprolactone pellets were milled at 8000 rpm in an Ultra Centrifugal Mill ZM 200 Retsch device. The powder obtained from the milling process was mixed with the appropriate amount of microcrystalline cellulose to obtain the following mixtures: PCL:MCC 98:2, PCL:MCC 95:5, PCL:MCC 90:10 and PCL:MCC 80:20. These blends were homogenized and, afterwards, they were subjected to a compression molding cycle in a Collin P $200 \mathrm{P} / \mathrm{M}$ press at $85^{\circ} \mathrm{C}$ and a pressure of 10 bar.

\subsection{In vitro swelling}

The in vitro swelling of the composite samples was evaluated both in phosphate buffered saline and water. For both liquids, the samples were maintained overnight in a desiccator and weighed in this state before immersion (dry mass, $\mathrm{md}$ ). The immersion times were $1 \mathrm{~h}, 2 \mathrm{~h}, 24 \mathrm{~h}$ and $48 \mathrm{~h}$. These periods were chosen in order to evaluate how long it takes to reach the equilibrium swelling. After these periods, the samples were removed and dried with filter paper in order to remove the excess of liquid. Once dried, they were weighed (wet mass, mw). This values allow determining water and PBS uptake according the equation (1):

$$
\% \text { Uptake }=100 \cdot\left(m_{w}-m_{d}\right) / m_{d}
$$

After determining the equilibrium swelling time following this gravimetric procedure, the samples were subjected to a more precise evaluation of the amount of water they are able to store by thermogravimetric analysis. Three replicas of each type of composite material were immersed in water for 48 hours. Afterwards, they were dried with filter paper and subjected to a thermal cycle consisting of a heating stage from $25^{\circ} \mathrm{C}$ to $200^{\circ} \mathrm{C}$ at $20^{\circ} \mathrm{C} / \mathrm{min}$. Afterwards, the temperature was steady at $200^{\circ} \mathrm{C}$ for 2 minutes. During the cycle an air flow of $10 \mathrm{ml} / \mathrm{min}$ was provided and alumina crucibles were used. This evaluation was carried out in a TGA/DSC 1 Mettler Toledo device. The 
mass loss values at $150^{\circ} \mathrm{C}$ were identified as the water released from the samples. Therefore, it was possible to correlate the water uptake from the samples with these values.

\subsection{Water contact angle}

The water contact angle was measured with a contact angle meter OCA15 Dataphysics at room temperature and the data were analysed with the SCA20 software. The liquids used were water and diiodomethane. This two substances were chosen because their difference of polarity to evaluate the surface energy by the application of the Owens, Wendt, Rabel and Kaelble method (Annamalai et al. 2016).

\subsection{Mechanical testing}

Four replicas of each material consisting of sheets of $60 \times 20 \mathrm{~mm} 2$ were obtained by compression molding and subjected to tensile testing. This testing was carried out in a Zwick Roell Z0.5 device in displacement control mode at a crosshead speed of $10 \mathrm{~mm} / \mathrm{min}$. The elastic modulus was evaluated as the slope of the initial segment of the stress-strain curve.

\subsection{Shore $D$ hardness}

The hardness of polycaprolactone and its composites was measured with a PCE-DD-D durometer (resolution 0.5 and accuracy \pm 2 ). Two sheets of material were piled up and 10 readings at different points of the surface were obtained.

\section{$2.7 \quad X$-Ray diffraction}

X-Ray diffraction (XRD) analysis was performed with an X-ray diffractometer (Bruker D8 Advance A25, with a $\mathrm{Cu}$ target, $\lambda=0.154 \mathrm{~nm}$ ). The samples were scanned from 3 to $90^{\circ}$. The system was operated at $40 \mathrm{kV}$ and a current of $20 \mathrm{~mA}$.

\subsection{Cell culture}

To analyze the effect of the additive in terms of cell attachment and proliferation, sheep bone marrow mesenchymal stem cells were cultured on the surface of PCL and composite samples.

Four $10 \mathrm{~mm}$ diameter discs of each blend of material (PCL, PCL:MCC 98:2, PCL:MCC 95:5, PCL:MCC 90:10 and PCL:MCC 80:20) were cut and sterilized by immersion in 70\% ethanol for 30 minutes. Afterwards, they were washed three times with PBS and three times with media to remove any trace of ethanol before carrying out the cell culture.

Regarding the seeding procedure, $50 \mu$ of media containing 30000 cells were seeded on each sample. The cells were allowed to attach to the surface for 1 hour in an incubator at $37^{\circ} \mathrm{C}$ and $5 \%$ $\mathrm{CO}_{2}$. After this time, $750 \mu \mathrm{l}$ of media were added and the samples were incubated for 8 days. The viability of the cells was analyzed after 1, 3 and 8 days of cell culture through the resazurin-based Presto Blue $\AA^{\circledR}$ assay. 


\section{RESULTS AND DISCUSSION}

\subsection{In vitro swelling}

The in vitro swelling has been pointed out as an indicator of the modification of the hydrophilicity of a material to be used for tissue engineering applications (Jonnalagadda et al. 2015). The results obtained during the present study can be observed in Figures 1 and 2.

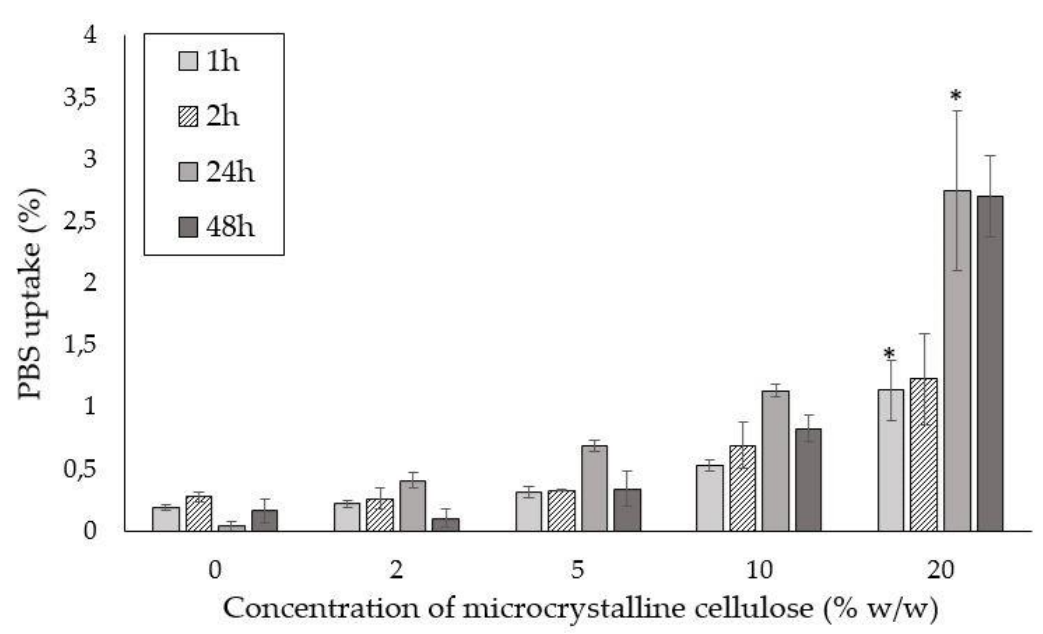

Figure 1. PBS uptake (\%) for $1 \mathrm{~h}, 2 \mathrm{~h}, 24 \mathrm{~h}$ and $48 \mathrm{~h}$ of immersion ( ${ }^{* *} \mathrm{p}<0.05$ compared to the group of pure PCL samples).

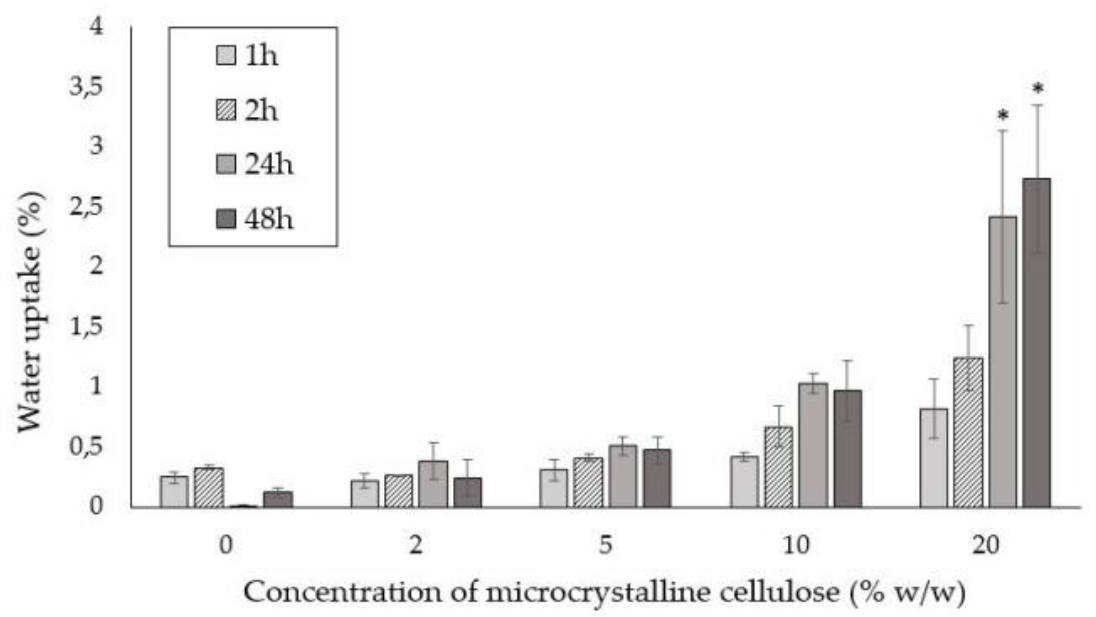

Figure 2. Water uptake (\%) for $1 \mathrm{~h}, 2 \mathrm{~h}, 24 \mathrm{~h}$ and $48 \mathrm{~h}$ of immersion $\left({ }^{* *} \mathrm{p}<0.05\right.$ compared to the group of pure PCL samples).

These in vitro swelling data show that microcrystalline cellulose increases the hydrophilicity of the samples and this increase is related to the content of the additive in the composite material, even for short periods of time. For example, during the first hour of immersion in PBS, PCL samples are able to uptake only a $0.19 \%$ from their initial mass value, while PCL:MCC $80: 20$ ones are able to uptake a $1.14 \%$ ( 6 times the referred amount for PCL). This behavior was previously observed for the loading with carboxymethylcellulose (Alemán-Domínguez et al. 2018a) and it entails a clear advantage when compared to other additives, like phosphate glass fiber. According to Liu et al. (Liu et al. 2014), filling polycaprolactone with phosphate glass fiber allows to increase the water uptake of the material, but periods of time larger than one day were required. However, when compared with polycaprolactone 
based composites obtained by carboxymethylcellulose (CMC) filling (Alemán-Domínguez et al. 2018a), it is possible to observe that microcrystalline cellulose composites are able to absorb lower amounts of water and PBS (at equilibrium water swelling time -48 hours- the value for PCL:CMC $80: 20$ was $6 \%$ and for the equivalent group of sample of PCL:MCC the value is $3 \%$ ).

Regarding the in vitro swelling equilibrium time, there is not significant difference $(p>0.05)$ between the uptake values at $24 \mathrm{~h}$ and $48 \mathrm{~h}$. Therefore, it is possible to confirm that at $24 \mathrm{~h}$ the material has reached the equilibrium of water and PBS uptake.

Regarding the more accurate data from the TGA analysis (Figure 3), it is possible to observe a correlation between the amount of water released during the thermal cycle and the concentration of the additive in the composite material. This correlation is a linear expression (shown in Figure 3 , $R^{2}=0.9834$ ), so the relationship between the presence of the microcrystalline cellulose in the composite materials and the increase in their hydrophilicity gets confirmed by this analysis.

The higher hydrophilicity of CMC-based composites is confirmed even clearer by the comparison of the equations from the thermogravimetric analysis. The equation that correlates water uptake to the concentration is a quadratic one when CMC is used as additive, but a linear one when the additive is microcrystalline cellulose.

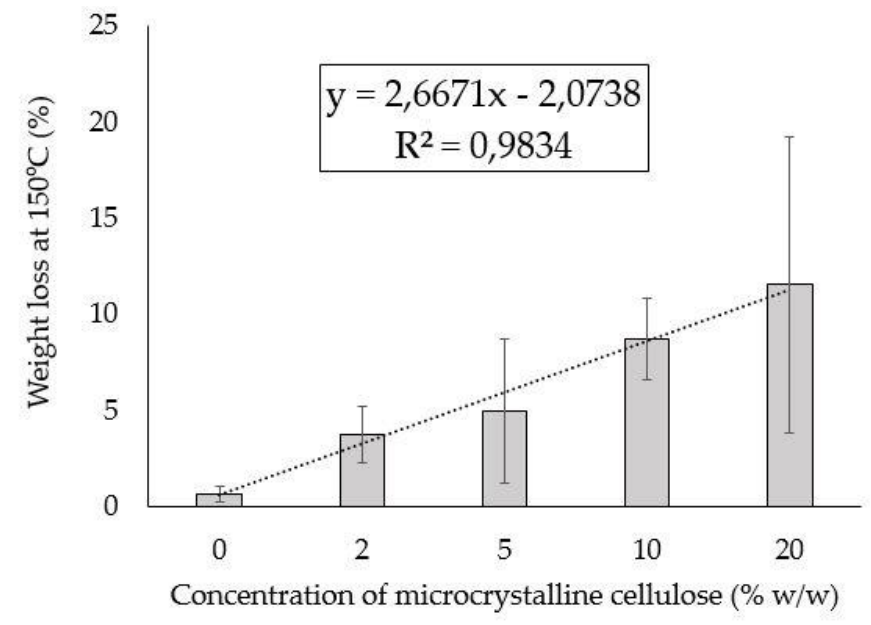

Figure 3. Correlation of weight loss at $150^{\circ} \mathrm{C}$ and the concentration of microcrystalline cellulose loaded in PCL matrices (measured by TGA).

\subsection{Water contact angle}

In Table 1 it is possible to observe the water and diiodomethane contact angles. It is possible to observe a decrease of the water contact angle when a $2 \%$ and a $5 \%$ wt:wt of microcrystalline cellulose is introduced in the matrix. However, for the samples containing a higher amount of additive, the water contact angle increases up to $95.2 \pm 2.7^{\circ}$ for PCL:MCC 80:20. On the other hand, a decrease in the diiodomethane water contact angle indicates that the surface becomes more hydrophobic (CanHerrera et al. 2016). In agreement with the data for water contact angle, the diiodomethane contact angle gets higher for the samples containing low concentrations of additive but it decreases when the concentration of microcrystalline cellulose reaches the $20 \%$ wt:wt. This trend confirms an increase of the hydrophilicity of the samples containing a low concentration of the additive. The results for the surface energy confirm this conclusion, as this parameter shows a maximum value for the group PCL:MCC 95:5. 


\begin{tabular}{|c|c|c|c|}
\hline \multicolumn{2}{|c|}{ Water contact angle } & \multicolumn{2}{|c|}{$\mathrm{CH}_{2} \mathrm{I}_{2}$ contact angle Surface energ } \\
\hline & $\overline{\text { degrees }}$ & degrees & $\overline{\mathrm{mN} / \mathrm{m}}$ \\
\hline$\overline{\mathrm{PCL}}$ & $87.1 \pm 3.8$ & $39.9 \pm 2.0$ & 39.20 \\
\hline $\begin{array}{l}\text { PCL:MCC } \\
98: 2\end{array}$ & $80.1 \pm 0.3 * *$ & $44.2 \pm 10.3$ & 41.50 \\
\hline $\begin{array}{l}\text { PCL:MCC } \\
95: 5\end{array}$ & $74.8 \pm 0.8 *$ & $41.1 \pm 10.2$ & 42.03 \\
\hline $\begin{array}{l}\text { PCL:MCC } \\
90: 10\end{array}$ & $85.3 \pm 2.7$ & $48.4 \pm 1.1^{* 8}$ & 35.67 \\
\hline $\begin{array}{l}\text { PCL:MCC } \\
80: 20\end{array}$ & $95.2 \pm 2.7^{* *}$ & $37.0 \pm 2.6^{*}$ & 38.75 \\
\hline
\end{tabular}

Table 1. Wettability data for $P C L$ and its composites $\left({ }^{*} p<0.05 ;{ }^{* *} p<0.01\right.$ compared to $P C L$ values).

\subsection{Mechanical testing}

The values of the tensile modulus of the composite materials increase with the amount of microcrystalline cellulose introduced in the blend, although this difference is significant only for those samples containing $20 \% \mathrm{w} / \mathrm{w}$ microcrystalline cellulose (Figure 4). It is important to notice that there is a linear trend between the values of the tensile modulus and the concentration of the additive in the blend.

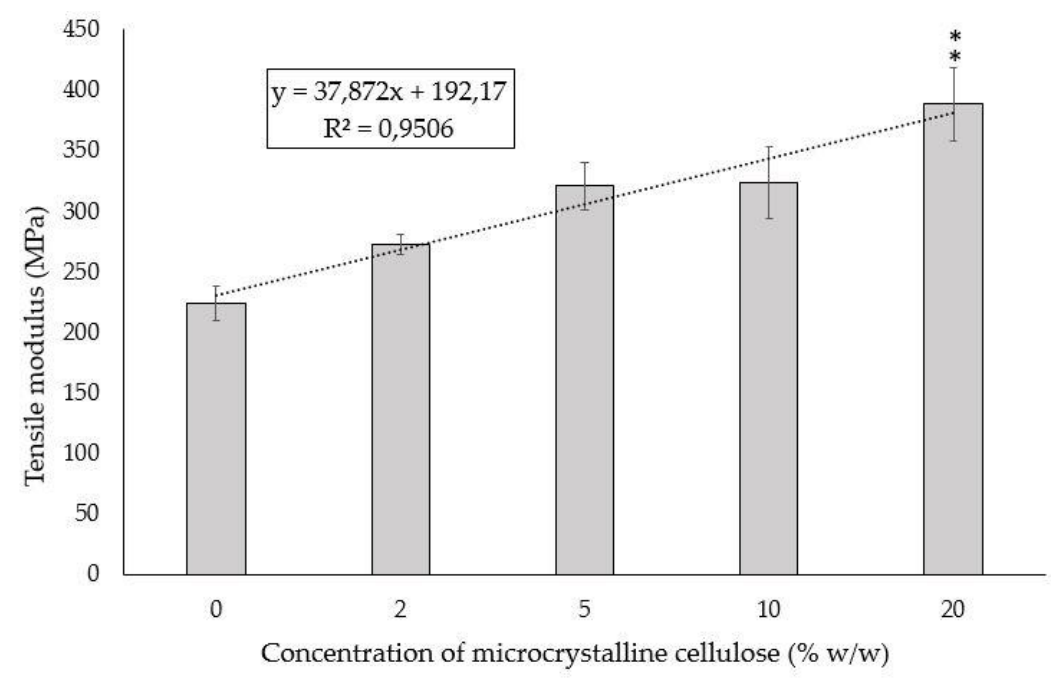

Figure 4. Mean values of the tensile modulus of composite materials and polycaprolactone $\left({ }^{* *} p<0.01\right.$ compared to the group of pure PCL samples).

However, this increment of the elastic modulus implies a more brittle behavior of the blend with the increase of the additive. As a consequence, the stress at yield point decreases, as it is possible to observe in Figure 5. This change of the thermoplastic matrix from the ductile behavior to the brittle or quasibrittle one is a common trend in composite materials where the filler is not a thermoplastic (Bazhenov 2011) because the filler particles act as discontinuity point in the matrix. 


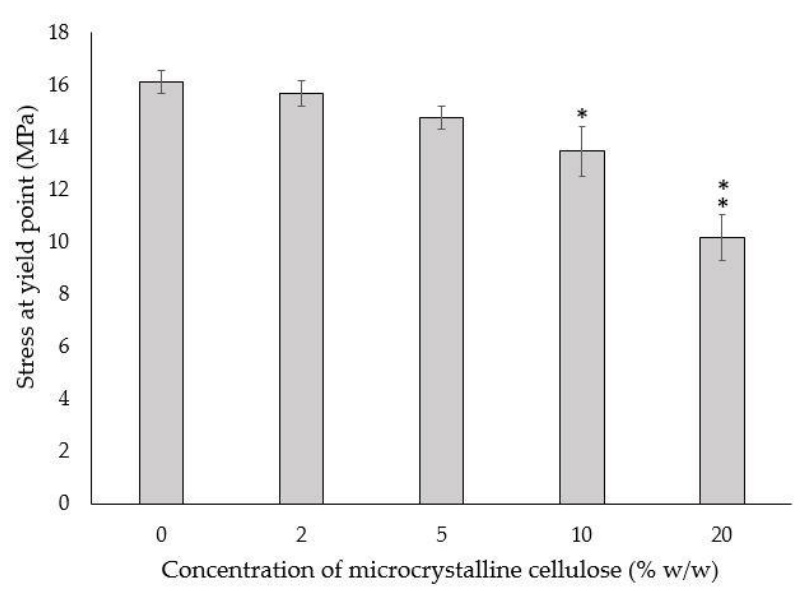

Figure 5. Mean values of the stress at yield point of composite materials and polycaprolactone $\left({ }^{* *} p<0.01\right.$ and ${ }^{*} p<0.05$ compared to the group of pure PCL samples).

The increase on the Young's modulus of the composite material has been reported for other fillers such as hydroxyapatite (Ródenas-Rochina et al. 2013, Rezai \& Mohammadi 2013) or bioglass (Ródenas-Rochina et al. 2013, Ji et al. 2015). The possibility of modifying the stiffness of the material with the concentration of the additive is highly relevant, as it is possible to find studies that state the relationship between the stiffness of the support material and the differentiation and migration processes of stem cells (Bracaglia et al. 2017, Engler et al. 2006).

\subsection{Shore D hardness}

The hardness of the materials slightly increases with the introduction of the additive (Table 2). The Shore $D$ of pure polycaprolactone is in accordance to the value from its datasheet. Hardness and stiffness are related parameters (Meththananda et al. 2009), so these results confirm the trend described by the mechanical characterization (Figure 4 and 5) about the increase in the stiffness of the composite material with the concentration of microcrystalline cellulose.

\begin{tabular}{lc}
\hline & Shore D hardness \\
\hline PCL & $50 \pm 2$ \\
PCL:MCC 98:2 & $50 \pm 2$ \\
PCL:MCC 95:5 & $52 \pm 2$ \\
PCL:MCC 90:10 & $52 \pm 2$ \\
PCL:MCC 80:20 & $55 \pm 3^{* *}$ \\
\hline
\end{tabular}

Table 2. Mean values of shore $D$ hardness of composite materials and polycaprolactone $\left({ }^{* \star} p<0.01\right)$.

\subsection{X-Ray diffraction}

Figure 6 shows the XRD pattern of PCL and their composites samples. All the diffractograms show the characteristic peaks of PCL at $21.3^{\circ}$ and $23.6^{\circ}$ which correspond to the (110) and (200) crystallographic planes of this semicrystalline polymer (Mirhosseini et al. 2016, Martins-Franchetti et al. 2010). Table 3 shows the values of the area of these two peaks for the different materials evaluated. The area of both peaks increases with the introduction of the additive with a maximum located at a concentration of $5 \% \mathrm{wt} / \mathrm{wt}$ of microcrystalline cellulose. 


\begin{tabular}{|c|c|c|}
\hline & Area of $21.3^{\circ}$ peak & \multirow{2}{*}{$\frac{\text { Area of } 21.3^{\circ} \text { peak }}{\text { a.u. }}$} \\
\hline & a.u. & \\
\hline PCL & 19238 & 3866 \\
\hline PCL:MCC 98:2 & 28059 & 7537 \\
\hline PCL:MCC 95:5 & 35072 & 10135 \\
\hline PCL:MCC 90:10 & 31256 & 9611 \\
\hline PCL:MCC 80:20 & 26360 & 6953 \\
\hline
\end{tabular}

Table 3. Area of the main XRD diffraction peaks.

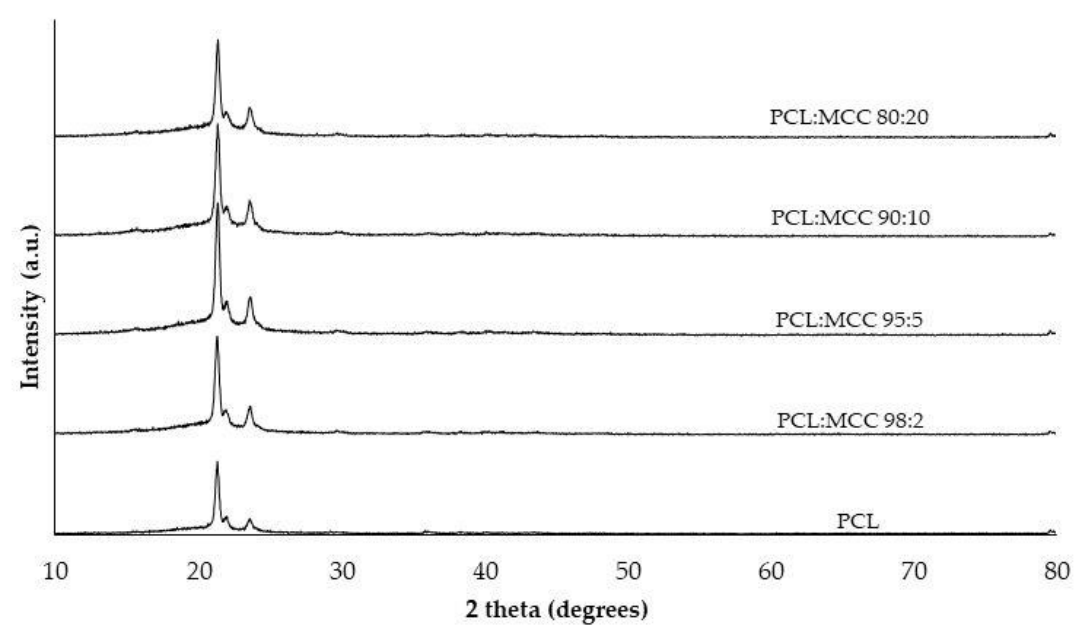

Figure 6. XRD patterns of PCL and its composites.

The sharper shape of the diffraction peaks at $21.4^{\circ}$ and $23.6^{\circ}$ and their increased area in the XRD patterns (Figure 6 and Table 3) can be related to an increment on the crystallinity of the matrix due to the presence of the filler particles. Therefore, the XRD data allow to confirm that the microcrystalline cellulose particles are able to act as nucleating points during the crystallization process. The increase in the crystallinity of the matrix explains the increase in the stiffness of the material confirmed by the tensile testing of the materials (Figure 4 and Figure 5 ) and the related increase in shore $D$ hardness (Table 2).

\subsection{Cell viability}

The results of the viability assay are shown in Figure 7. From Day 3 to Day 8, the population increases on all the groups of samples analyzed. This fact confirms the biocompatibility of the different composite materials in terms of cell viability. The fluorescence at the end of the experiment (Day 8) is higher for the samples with microcrystalline cellulose than for those without additive.

It has been possible to confirm that the introduction of the microcrystalline cellulose has a concentration-dependent effect: the fluorescence at Day 8 is increased for the samples containing 2 and $5 \% \mathrm{w} / \mathrm{w}$ of microcrystalline cellulose. For the samples containing 10 and $20 \% \mathrm{w} / \mathrm{w}$, the values are still higher than the PCL one, but it is possible to observe a diminishment compared to the values obtained for the samples containing $5 \% \mathrm{w} / \mathrm{w}$ of microcrystalline cellulose (Figure 7 ). This concentration-dependent behaviour has been previously reported for other composite biomaterials, 
such as polylactic acid filled with Bioglass ${ }^{\circledR}$ (Verrier et al. 2004) or polycaprolactone filled with hydroxyapatite(Ródenas-Rochina et al. 2013). The maximum fluorescence, related to the maximum cell affinity, is therefore observed for the group of samples containing $5 \%$ microcrystalline cellulose. This fact could be explained by the increase of surface wettability (Table 1). As previously described, the surface energy shows a maximum for the PCL:MCC 95:5 group, so this characteristic could have direct implications on the cell affinity of the samples. However, when compared these data to the previously reported for PCL:MCC 3D printed structures,(Alemán-Domínguez et al. 2018b) it is possible to observe a modification of the position of the cell viability maximum. In that case, it was located at $2 \% \mathrm{wt} / \mathrm{wt}$ content of microcrystalline cellulose. This change could be explained by the effect of the presence of the additive on the morphology of the surface of the 3D printed samples. The modifications of the morphology of the filaments have a definite effect on cell attachment and proliferation. Therefore, these results confirm the positive influence of the filling with microcrystalline cellulose and how the manufacturing process can modify the biological performance of the composite materials.

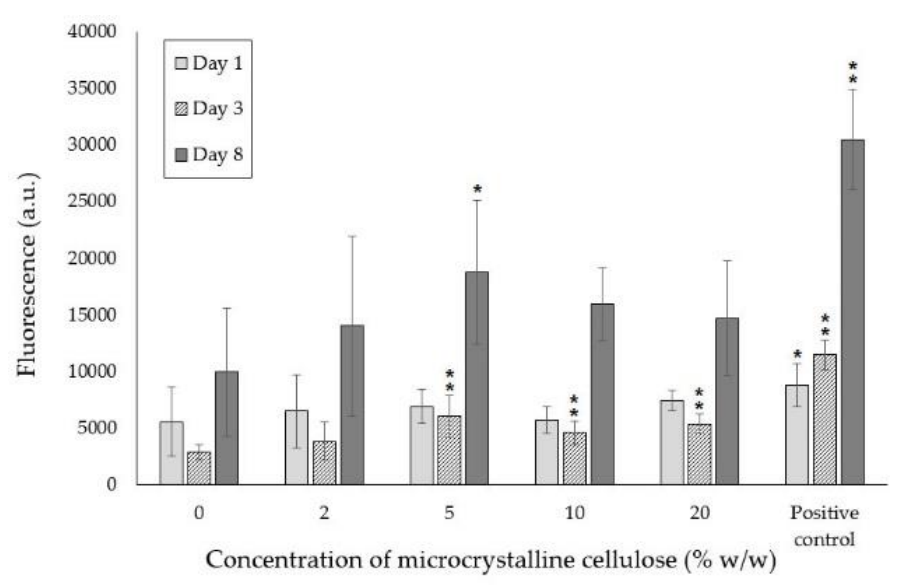

Figure 7. Results of viability tests for PCL:MCC composites using Presto Blue ${ }^{\circledR}$ assay $\left({ }^{*} p<0.05 ;{ }^{* *} p<0.01\right.$ compared to the group of pure PCL samples).

Besides, when these data are compared to the data from polycaprolactone:carboxymethylcellulose composites (Alemán-Domínguez et al. 2018a), it is possible to confirm that microcrystalline cellulose provides an improvement on cell affinity that carboxymethylcellulose cannot offer. It is possible that the water affinity of the composite materials plays a role in this behavior. As stated above, for polycaprolactone:carboxymethylcellulose composites, water and PBS uptake values were higher. It can be stated that these values were high enough to hinder the adsorption of adhesion-signaling extracellular proteins (Alemán-Domínguez et al. 2018a, Chen et al. 2018). For PCL:MCC composites obtained in the present study, however, the hydrophilicity is kept within the values able to provide an improvement on cell proliferation.

Nevertheless, the processes that rule the attachment and proliferation of cells on biomaterials are complex and several parameters are involved, such as wettability, topography or surface charge (Chen et al. 2018). It would be interesting for future work to deeper analyze the influence of these parameters on the biological performance of polycaprolactone:microcrystalline cellulose composites. 
The introduction of microcrystalline cellulose has a significant influence in the properties of polycaprolactone based composites. The results obtained in this study show the reinforcement effect that can be obtained by filling PCL with this additive. Besides, the composite materials have a higher bioaffinity for sheep bone marrow mesenchymal cells than pure polycaprolactone.

\section{ACKNOWLEDGMENTS}

The authors would like to thank H2020-MSCA-RISE program through the BAMOS project, funded from the European Union's Horizon 2020 research and innovation programme under grant agreement № 734156. They would like to thank also the project DPI2017-88465-R funded by the Science, Innovation and Universities Spanish Ministry.

M.E. Alemán-Domínguez would like to express her gratitude for the funding through the PhD Grant Program of ULPGC (PIFULPGC-2014-ING-ARQU-2).

\section{REFERENCES}

Alemán-Domínguez ME, Ortega Z, Benítez AN, Vilariño-Feltrer G, Gómez-Tejedor JA, Vallés-Lluch A. 2018a J Appl Polym Sci. 13546134

Alemán-Domínguez ME, Giusto E, Ortega Z, Tamaddon M, Benítez AN, Liu C. Three-dimensional printed polycaprolactone-microcrystalline cellulose scaffolds. 2018b J Biomed Mater Res B.

Annamalai M, Gopinadhan K, Han SA, Saha S, Park HJ, Cho EB, et al. 2016 Nanoscale 85764

Bazhenov S. 2011 in Cuppoletti J (ed)Metal, Ceramic and Polymeric Composites for Various Uses (InTech) p171

Bracaglia LG, Smith BT, Watson E, Arumugasaamy N, Mikos AG, Fisher JP. 2017 Acta Biomater.56 3

Can-Herrera LA, Ávila-Ortega A, de la Rosa-García S, Oliva Al, Cauich-Rodríguez JV, Cervantes-Uc JM. 2016 Eur Polym $\mathrm{J} 84502$

Chen S, Guo Y, Liu R, Wu S, Fang J, Huang B, et al. 2018Colloid Surface B.164 58

Domingos M, Gloria A, Coelho J, Bartolo P, Ciurana J. 2017Proceedings of the Institution of Mechanical Engineers, Part $\mathrm{H}$ : Journal of Engineering in Medicine. 231555

Drummer D, Cifuentes-Cuéllar S, Rietzel D. 2012 Rapid Prototyping J.18500

Engler AJ, Sen S, Sweeney HL, Discher DE. 2006Cell126677

Haafiz MKM, Hassan A, Zakaria Z, Inuwa IM, Islam MS, Jawaid M. 2013Carbohyd Polym. 98139

Izzati Zulkifli N, Samat N, Anuar H, Zainuddin N. 2015Materials and Design 69114

Ji L, Wang W, Jin D, Zhou S, Song X. 2015Mat Sci Eng C-Mater.46 1

Jonnalagadda JB, Rivero IV, Warzywoda J. 2015J Biomater App30 472

Lin YH, Chiu YC, Shen YF, Wu YHA, Shie MY. 2018J Mater Sci-Mater M.29

Liu X, Hasan MS, Grant DM, Harper LT, Parsons AJ, Palmer G, et al. 2014 J Biomater App29675

Martins-Franchetti SM, Egerton TA, White JR. 2010J Polym Environ18 79

Mehr NG, Li X, Chen G, Favis BD, Hoemann CD. 2015J Biomed Mater Res A.103 2449

Meththananda IM, Parker S, Patel MP, Braden M. 2009Dental Materials25956

Mirhosseini MM, Haddadi-AsI V, Zargarian SS. 2016J Appl Polym Sci.13343345

Mondal D, Griffith M, Venkatraman SS. 2016Int J Polym Mater Po.65 255

Nyberg E, Rindone A, Dorafshar A, Grayson WL. 2017Tissue Engineering - Part A.23 503

Park SA, Lee SH, Kim WD. 2011Bioprocess and Biosystems Engineering.34 505

Rezaei A, Mohammadi MR. 2013Mat Sci Eng C-Mater.33390

Ródenas-Rochina J, Ribelles JLG, Lebourg M. 2013J Mater Sci-Mater M. 241293

Verrier S, Blaker JJ, Maquet V, Hench LL, Boccaccini AR. 2004 Biomaterials25 3013 